\title{
RK-270A - C, new oxindole derivatives isolated from a microbial metabolites fraction library of Streptomyces sp. RK85-270
}

\author{
Jun-Pil Jang ${ }^{1,2}$, Toshihiko Nogawa ${ }^{3}$, Masakazu Uramoto ${ }^{3}$, Akiko Okano ${ }^{3}$, Yushi Futamura ${ }^{4}$, Takeshi Shimizu ${ }^{3}$, \\ Shunji Takahashi ${ }^{1,3}$, Jae-Hyuk Jang ${ }^{2}$, Jong Seog $\mathrm{Ahn}^{2}$ and Hiroyuki Osada ${ }^{3}$
}

The Journal of Antibiotics (2015) 68, 293-295; doi:10.1038/ja.2014.141; published online 15 October 2014

Three new oxindole derivatives, RK-270A (1), B (2) and C (3) (Figure 1), were discovered and isolated from Streptomyces sp. RK85270. They had an isopropylidene group at C-3 position of an oxindole skeleton, and C-1 also had a prenyl group and belonged to a class of 6-prenylated indoles. The isolation of this type of indoles was the first example as a natural product. Their cytotoxicity and antibacterial activities were evaluated.

Secondary metabolites from microorganisms are a major source of pharmaceutical leads and therapeutic agents ${ }^{1}$ or bioprobes in a chemical biology study. ${ }^{2}$ To obtain such valuable metabolites efficiently we have constructed a microbial metabolites fraction library and a spectral database based on the photodiode array detector attached LC/MS analysis. ${ }^{3,4}$ Through our methodology, we have identified several structurally unique metabolites, verticilactam, ${ }^{5}$ spirotoamides $\mathrm{A}$ and $\mathrm{B},{ }^{6}$ pyrrolizilactone, ${ }^{7}$ fraquinocins $\mathrm{I}$ and $\mathrm{J}^{8}$ and 6-dimethylallylindole (DMAI)-3-carbaldehyde. ${ }^{9}$ Moreover, we recently reported the advanced metabolite database Natural Products Plot (NPPlot) and discovery of new quinomycins, RK-1355A and B by the NPPlot search. ${ }^{10}$ These results have revealed the advantage of the fraction library for isolation of new metabolites.

The fraction library of Streptomyces sp. RK85-270, which was isolated from a soil sample collected in Java, Indonesia in 1985, was prepared from 301 of culture broth following the scheme as described in the previous paper. ${ }^{3-6}$ On screening for structurally unique secondary metabolites using the database, we identified three unknown peaks with identical UV, which showed characteristic UV absorption with around 260, 265 and $300 \mathrm{~nm}$ indicating an indole chromophore with extended conjugation. They also showed quasimolecular ion peaks at 242, 276 and $271[\mathrm{M}+\mathrm{H}]^{+}$, respectively. The related fractions were purified by $\mathrm{C}_{18}$-HPLC with acetonitrile/water isocratic elution to yield compounds $\mathbf{1}(1.2 \mathrm{mg}), 2(1.4 \mathrm{mg})$ and 3
(1.3 mg) (see Supplementary Information for physicochemical properties). We report herein the structures of these three new compounds designated RK-270A (1), B (2) and C (3).

Compound 1 was obtained as an orange amorphous powder, and its molecular formula was determined to be $\mathrm{C}_{16} \mathrm{H}_{19} \mathrm{NO}$ by HRESIMS $\left(\mathrm{m} / z 242.1542[\mathrm{M}+\mathrm{H}]^{+}\right.$, calcd for $\left.\mathrm{C}_{16} \mathrm{H}_{20} \mathrm{NO}, 242.1545\right)$. The IR spectrum implied the presence of an amide carbonyl group (1687 and $\left.1617 \mathrm{~cm}^{-1}\right)$. The ${ }^{1} \mathrm{H}$ NMR spectrum in DMSO- $d_{6}$ showed four methyl signals $\left(\delta_{\mathrm{H}} 1.67(3 \mathrm{H}, \mathrm{s}), 1.69(3 \mathrm{H}, \mathrm{s}), 2.26(3 \mathrm{H}, \mathrm{s})\right.$ and 2.47 $(3 \mathrm{H}, \mathrm{s}))$ (Table 1$)$. Two of them $\left(\delta_{\mathrm{H}} 1.67\right.$ and 1.69) suggested the presence of a prenyl group with olefin and methylene signals $\left(\delta_{\mathrm{H}} 5.26\right.$ $(1 \mathrm{H}, \mathrm{m}), 3.26(2 \mathrm{H}, \mathrm{d}, J=7.4 \mathrm{~Hz}))$. It also showed an exchangeable $\mathrm{NH}$ proton $\left(\delta_{\mathrm{H}} 10.31(1 \mathrm{H}\right.$, broad singlet; brs $\left.)\right)$ and three aromatic resonances with $\mathrm{AB}-\mathrm{X}$ pattern $\left(\delta_{\mathrm{H}} 7.40(1 \mathrm{H}, \mathrm{d}, J=8.0 \mathrm{~Hz}), 6.74\right.$ $(1 \mathrm{H}, \mathrm{dd}, J=8.0,1.1 \mathrm{~Hz})$ and $6.60(1 \mathrm{H}, \mathrm{d}, J=1.1 \mathrm{~Hz}))$ suggesting the presence of a trisubstituted benzene ring, which was supposed to be a part of an indole skeleton. The ${ }^{1} \mathrm{H}$ and ${ }^{13} \mathrm{C}$ NMR data in conjunction with the HSQC data suggested the presence of 16 carbons, comprising four methyls, one methylene, four methins and seven quaternary carbons, which included an amide carbonyl signal at $\delta_{\mathrm{C}} 168.8$. In the HSQC spectrum in DMSO- $d_{6}$, the correlation between H-10 and C-10 was observed as a very weak signal, therefore it was confirmed by $\mathrm{HSQC}$ spectrum in $\mathrm{CDCl}_{3}$. Interpretation of the $2 \mathrm{D} \mathrm{NMR}$ data including DQF-COSY, HSQC and HMBC spectra led to the construction of precise structure of $\mathbf{1}$ (Figure 2). The HMBC correlations from $\mathrm{NH}$ signal to $\mathrm{C}-3$ and $\mathrm{C}-7 \mathrm{a}$, from $\mathrm{H}-4$ to $\mathrm{C}-3, \mathrm{C}-6$ and $\mathrm{C}-7 \mathrm{a}$, from $\mathrm{H}-5$ to $\mathrm{C}-3 \mathrm{a}$ and $\mathrm{C}-7$ and from $\mathrm{H}-7$ to $\mathrm{C}-3 \mathrm{a}$ constructed an oxindole skeleton and substitutions at C-3 and C-6 positions in the oxindole skeleton in consideration of $\mathrm{AB}-\mathrm{X}$ coupling pattern in ${ }^{1} \mathrm{H}$ NMR spectra, ${ }^{13} \mathrm{C}$ NMR data and IR spectrum. The isopropylidene moiety and its attachment at C-3 position was confirmed by HMBC

${ }^{1}$ RIKEN Global Research Cluster, Wako, Saitama, Japan; ${ }^{2}$ Chemical Biology Research Center, Korea Research Institute of Bioscience and Biotechnology (KRIBB), Ochang, Republic of Korea; ${ }^{3}$ RIKEN Center for Sustainable Research Science, Saitama, Japan and ${ }^{4}$ The Viral Hepatitis Research Foundation of Japan, Tokyo, Japan

Correspondence: Dr JS Ahn, Chemical Biology Research Center, Korea Research Institute of Bioscience and Biotechnology (KRIBB), 30 Yeongudanji-ro, Ochang-eup, Cheongwon-gun, Chungbuk 363-883, Republic of Korea.

E-mail: jsahn@kribb.re.kr

or Dr H Osada, RIKEN Center for Sustainable Research Science, 2-1 Hirosawa, Wako, Saitama 351-0198, Japan.

E-mail: hisyo@riken.jp

Received 18 June 2014; revised 8 September 2014; accepted 16 September 2014; published online 15 October 2014 
<smiles>CC(C)=CCc1ccc2c(c1)NC(=O)C2=C(C)C</smiles>

1<smiles>CC(C)=C1C(=O)Nc2cc(CC(C)C(C)(C)O)ccc21</smiles>

2

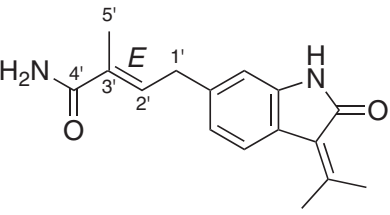

3

Figure 1 Structures of compounds 1, 2 and 3.

Table 1 NMR spectroscopic data $(500 \mathrm{MHz})$ for compounds 1,2 and 3

\begin{tabular}{|c|c|c|c|c|c|c|}
\hline \multirow[b]{2}{*}{ Position } & \multicolumn{2}{|r|}{$1^{\mathrm{a}}$} & \multicolumn{2}{|r|}{$2^{\mathrm{a}}$} & \multicolumn{2}{|r|}{$3^{\mathrm{a}}$} \\
\hline & $\delta_{C}$ & $\delta_{H}(\mathrm{~J}$ in $\mathrm{Hz})$ & $\delta_{C}$ & $\delta_{H}(\mathrm{~J}$ in $\mathrm{Hz})$ & $\delta_{C}$ & $\delta_{H}(\mathrm{~J}$ in $\mathrm{Hz})$ \\
\hline 2 & 168.8 & - & 168.9 & - & $169.3^{c}$ & - \\
\hline 3 & 122.7 & - & 122.8 & - & 123.1 & - \\
\hline 3a & 121.4 & - & 121.2 & - & 122.3 & - \\
\hline 6 & 141.2 & - & 141.4 & - & 140.0 & - \\
\hline 7 & 108.8 & $6.60, d(1.1)$ & 110.0 & $6.71, d(1.1)$ & 109.6 & $6.63, d(1.2)$ \\
\hline $7 a$ & 140.6 & - & 140.2 & - & 141.2 & - \\
\hline 8 & 152.5 & - & 152.0 & - & 153.5 & - \\
\hline 9 & 24.7 & $2.26, \mathrm{~s}$ & 24.7 & $2.27, \mathrm{~s}$ & 25.3 & $2.28, \mathrm{~s}$ \\
\hline $3^{\prime}$ & 131.9 & - & 71.7 & - & 132.6 & - \\
\hline $4^{\prime}$ & 25.5 & $1.69, \mathrm{~s}$ & 24.0 & $1.05, \mathrm{~s}$ & $170.5^{b}$ & - \\
\hline $5^{\prime}$ & 17.7 & $1.67, \mathrm{~s}$ & 26.9 & $1.10, \mathrm{~s}$ & 13.3 & $1.82, \mathrm{~d}(1.2)$ \\
\hline $2^{\prime}-\mathrm{OH}$ & - & - & - & 4.44 , brs & - & - \\
\hline $3^{\prime}-\mathrm{OH}$ & - & - & - & 4.26 , brs & - & - \\
\hline $4^{\prime}-\mathrm{NH}_{2}$ & - & - & - & - & - & 6.87, brs \\
\hline & & & & & & 7.32, brs \\
\hline
\end{tabular}

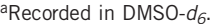

bbrs: broad singlet.

${ }^{\mathrm{C}}$ Indicated carbons showed only weak resonances in the ${ }^{13} \mathrm{C}$ NMR spectrum, but their presence and connectivity were clearly evidenced by all conducted $2 \mathrm{D}$ NMR experiments.

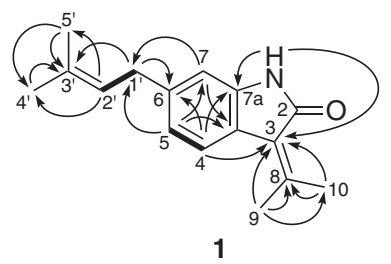

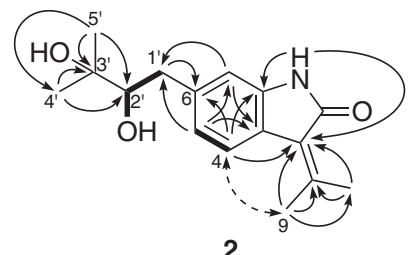

2

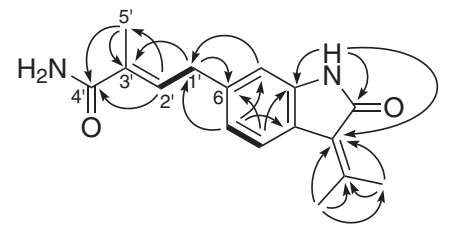

3

Figure 2 Key 2D NMR correlations of 1, 2 and 3

correlations from both H-9 and H-10 to C-8, from H-9 to C-10, and from both $\mathrm{H}-9$ and $\mathrm{H}-10$ to C-3. The assignments of C-9 and C-10 signals were established by the low field chemical shift value of $\mathrm{H}-10$ rather than that of $\mathrm{H}-9$. The prenyl group was constructed by $\mathrm{HMBC}$ correlations from $\mathrm{H}-1^{\prime}$ to $\mathrm{C}-3^{\prime}$, from $\mathrm{H}-2^{\prime}$ to both $\mathrm{C}-4^{\prime}$ and $\mathrm{C}-5^{\prime}$, from both $\mathrm{H}-4^{\prime}$ and $\mathrm{H}-5^{\prime}$ to $\mathrm{C}-3$ and from $\mathrm{H}-5^{\prime}$ to $\mathrm{C}-4^{\prime}$. The attachment of the prenyl group was established by $\mathrm{HMBC}$ correlation from both $\mathrm{H}-5$ and $\mathrm{H}-7$ to $\mathrm{C}-1^{\prime}$ and from $\mathrm{H}-1^{\prime}$ to $\mathrm{C}-6$. The assignment of $\mathrm{C}-4^{\prime}$ and $\mathrm{C}-5^{\prime}$ signals were performed owing to their chemical shifts $\left(\delta_{\mathrm{C}} 17.7\left(\mathrm{C}-5^{\prime}\right)\right.$ and $\left.25.5\left(\mathrm{C}-4^{\prime}\right)\right)$. Thus, the structure of 1 was designated as RK-270A.

The molecular formula of compound 2 was determined to be $\mathrm{C}_{16} \mathrm{H}_{21} \mathrm{NO}_{3}$ by HRESIMS. The IR absorption at 1683 and $1622 \mathrm{~cm}^{-1}$ and identical UV spectrum with that of 1 suggested that 2 had the same oxindole skeleton as $\mathbf{1}$. However, the IR spectrum showed an additional absorption at $3388 \mathrm{~cm}^{-1}$, indicating the presence of a 
hydroxyl group. The ${ }^{1} \mathrm{H}$ NMR spectrum in DMSO- $d_{6}$ was also similar to that of 1 , except for the disappearance of the olefin proton and appearance of two exchangeable signals at $\delta_{\mathrm{H}} 4.44$ and 4.26 as broad signals and an oxymethine signal at $\delta_{\mathrm{H}} 3.27$, which were confirmed by HSQC spectrum. The ${ }^{13} \mathrm{C}$ NMR spectrum in DMSO- $d_{6}$ showed 16 signals including identical signals for the oxindole skeleton with those of 1 . However, the olefin signals were disappeared and two oxygenated signals at $\delta_{\mathrm{C}} 71.7$ as a quaternary one and $\delta_{\mathrm{C}} 79.1$ as a methine were observed. On the basis of the above observation, 2 was supposed to be a dihydroxylated derivative of $\mathbf{1}$ at the $\Delta^{2^{\prime}}$. The planner structure of $\mathbf{2}$ was established by the same manner as 1 . The assignments of C-9 and $\mathrm{C}$-10 were established by their ${ }^{1} \mathrm{H}$ NMR chemical shift values and confirmed by NOESY correlation between $\mathrm{H}-4$ and H-9 (Figure 2). To determine the absolute configuration for C-2', preparation of the ester of 2 using $\alpha$-methoxy- $\alpha$-trifluoromethylphenylacetatic acid (MTPA) or $\alpha$-methoxy- $\alpha$-trifluoromethylphenylacetyl chloride (MTPACl) were carried out by application of the modified Mosher's method (see Supplementary Information for detail). ${ }^{11}$ However, all of the approaches employed did not yield the desired product. Therefore, the optical rotation value of 2 was compared with those of $(R)-6-(2,3-$ dihydroxy-3-methylbutyl)indole and $(R)$-6-(2,3-dihydroxy-3-methylbutyl)indolin-2-one. ${ }^{12}$ Compound 2 displayed a negative optical rotation as same as the literature. Thus, the absolute configuration at $\mathrm{C}-2^{\prime}$ was supposed to be $R$-configuration, and the structure of $\mathbf{2}$ was designated as RK-270B.

Compound 3 had a molecular formula of $\mathrm{C}_{16} \mathrm{H}_{18} \mathrm{~N}_{2} \mathrm{O}_{2}$ determined by HRESIMS. The ${ }^{1} \mathrm{H}$ and ${ }^{13} \mathrm{C}$ NMR spectra in DMSO- $d_{6}$ were similar to those of $\mathbf{1}$ for the oxindole skeleton with isopropylidene group at C-3, which was also supported by the identical UV spectrum and similar IR spectrum with those of $\mathbf{1}$. However, one methyl signal was disappeared and two exchangeable signals assigned as $\mathrm{NH}_{2}$ protons $(\delta \mathrm{H} 7.32(1 \mathrm{H}$, brs $)$ and $6.87(1 \mathrm{H}$, brs $))$ were observed in the ${ }^{1} \mathrm{H}$ NMR spectrum of 3 . In addition, the ${ }^{13} \mathrm{C}$ NMR spectrum showed the additional carbonyl carbon at $\delta_{\mathrm{C}} 170.5$ as a weak signal, which was clearly observed by the $\mathrm{HMBC}$ correlations and confirmed by ${ }^{13} \mathrm{C}$ NMR data obtained in $\mathrm{CD}_{3} \mathrm{OD}$, and the missing of one methyl signal. These observation suggested that one of the methyl groups at C- $3^{\prime}$ of 1 was replaced by an amide group. The detailed structure was determined by the same manner as $\mathbf{1}$ and $\mathbf{2}$ (Figure 2) and designated as RK-270C.

Compounds 1, 2 and 3 were evaluated for cytotoxic activity against human cervical cancer cells (HeLa), human promyelocytic leukemia cells (HL-60), mouse temperature-sensitive cdc2 mutant cells (tsFT210) and rat kidney cells that were infected with ts25 ( $s \mathrm{rc}^{\mathrm{ts}}$ NRK) and antimicrobial activity against Staphylococcus aureus, Escherichia coli, Aspergillus fumigatus, Magnaporthe oryzae and Candida albicans. Compound $\mathbf{1}$ showed moderate cytotoxicity against all of four cell lines with $\mathrm{IC}_{50}$ values of $6.6,5.5,10.9$ and $15.3 \mu \mathrm{g} \mathrm{ml}^{-1}$, respectively. Compound 1 also showed weak antifungal activity against M. oryzae with $\mathrm{IC}_{50}$ value of $8.7 \mu \mathrm{g} \mathrm{ml}^{-1}$ In contrast, 2 and 3 did not show any effects up to $30 \mu \mathrm{g} \mathrm{ml}^{-1}$. These results suggest that the prenyl group is important for the activities, which will be an important knowledge for future SAR study.

Three new oxindole derivatives, RK-270A (1), B (2) and C (3) were isolated from Streptomyces sp. RK85-270 based on our methodology constructing the fraction library with spectral database. They had an isopropylidene group at C-3 position and prenyl group or its related side chains at C-6 position. Even though prenylated indole derivatives are widely distributed in nature, ${ }^{13}$ the isolation of the prenylated oxindole with the isopropylidene group at C-3 position is the first example as a natural product. We have reported the isolation of the new prenylated indole, 6-DMAI-3-carbaldehyde from Stretomyces. sp. $\mathrm{SN}-593$ and identified the key enzyme (IptA) for the prenylation at C-6 position. ${ }^{9}$ Recently, Satou et al. ${ }^{14}$ have reported the isolation of 3hydroxy-6-dimethylallylindolin-2-one from Actinoplanes missouriensis and its biosynthetic pathway. However, a gene responsible for oxindole formation still remains unsolved. In addition, conversion of 1 into 2 and 3 requires successive hydroxylation and carboxamide formation. Identification of the gene cluster of $\mathbf{1 - 3}$ is indispensable to address the mechanism of biosynthesis and future derivatization of oxindoles which might have a strong biological activity.

\section{ACKNOWLEDGEMENTS}

We thank Dr T Nakamura and Dr Y Hongo in RIKEN for the HRESIMS measurements and Ms $\mathrm{H}$ Aono and Ms N Morita in RIKEN for activity tests. We also thank Dr H Kusakabe in RIKEN for the collection of the strain. This work was supported in part by a Grant-in-Aid for Scientific Research (A) from the Ministry of Education, Culture, Sports and Technology of Japan, the Program for Promotion of Basic and Applied Researches for Innovations in Bio - oriented Industry and Health and Labour Sciences Research Grant. This work was also supported in part by grants of KRIBB Research Initiative Program and GRDC Program of NRF funded from Ministry of Science, ICT and Future Planning of Korea.

1 Newman D. J., Cragg G. M. Natural products as sources of new drugs over the 30 years from 1981 to 2010. J. Nat. Prod. 2012; 75: 311-335.

2 Osada, H. Chemical biology based on small molecule-protein interaction. Protein targeting with small molecules. Chemical Biology Techniques and Applications (ed. Osada, H.) 1-10 (Wiley, New Jersey, 2009).

3 Osada, H., Nogawa, T. Systematic isolation of microbial metabolites for natural products depository (NPDepo). Pure Appl. Chem. 84, 1407-1420 (2012).

4 Kato, N., Takahashi, S., Nogawa, T., Saito, T., Osada, H. Construction of a microbial natural product library for chemical biology studies. Curr. Opin. Chem. Biol. 16, 101-108 (2012).

5 Nogawa, T. et al. Verticilactam, a new macrolactam isolated from a microbial metabolite fraction library. Org. Lett. 12, 4564-4567 (2010).

6 Nogawa, T. et al. Spirotoamides A and B, novel 6,6-spiroacetal polyketides isolated from a microbial metabolite fraction library. J. Antibiot. 65, 123-128 (2012).

7 Nogawa, T. et al. Pyrrolizilactone, a new pyrrolizidinone metabolite produced by a fungus. J. Antibiot. 66, 621-623 (2013).

8 Panthee, S. et al. Furaquinocins I and J: novel polyketide isoprenoid hybrid compounds from Streptomyces reveromyceticus SN-593. J. Antibiot. 64, 509-513 (2011).

9 Takahashi, S. et al. Biochemical characterization of a novel indole prenyltransferase from Streptomyces sp. SN-593. J. Bacteriol. 192, 2839-2851 (2010).

$10 \mathrm{Lim}$, C.-L. et al. RK-1355A and B, novel quinomycin derivatives isolated from a microbial metabolites fraction library based on NPPlot screening. J. Antibiot. 67, 323-329 (2014).

11 Ohtani, I., Kusumi, T., Kashman, Y., Kakisawa, H. High-field FT NMR application of Mosher's method. The absolute configurations of marine terpenoids. J. Am. Chem. Soc. 113, 4092-4096 (1991).

12 Zheng, D. et al. Structure elucidation of four prenylindole derivatives from Streptomyces sp. isolated from Ailuropoda melanoleuca feces. Magn. Reson. Chem. 51, 188-191 (2013).

13 Williams, R. M., Stocking, E. M., Sanz-Cervera, J. F. Biosynthesis of prenylated alkaloids derived from tryptophan. Topics Curr. Chem. 209, 97-173 (2000).

14 Satou, R. et al. Isolation, structural elucidation and biosynthesis of 3-hydroxy-6dimethylallylindolin-2-one, a novel prenylated indole derivative from Actinoplanes missouriensis. J. Antibiot. 67, 231-236 (2014).

Supplementary Information accompanies the paper on The Journal of Antibiotics website (http://www.nature.com/ja) 